\title{
Nephron Sparing Surgery in Renal Allograft in Recipients with de novo Renal Cell Carcinoma: Two Case Reports and Review of the Literature
}

\author{
Mandy Hubatsch Robert Peters Andreas Maxeiner Nasrin El-Bandar \\ Sarah Weinberger Frank Friedersdorff \\ Department of Urology, Charité - Universitätsmedizin Berlin, Corporate member of Freie Universität Berlin, \\ Humboldt-Universität zu Berlin, and Berlin Institute of Health, Berlin, Germany
}

\section{Keywords}

Renal cell carcinoma - Kidney transplantation .

Posttransplant malignancy · Nephron sparing surgery

\begin{abstract}
We report 2 cases of de novo renal cell carcinoma (RCC) in renal grafts after transplantation. Both patients underwent nephron sparing surgery (NSS) 211 and 167 months after transplantation, revealing papillary RCC with a tumour size $>4 \mathrm{~cm}$ (pT1a). Within a follow-up of 25 and 32 months after NSS, a stable renal function without indication for dialysis was present. No recurrence of RCC in both cases was reported within the yearly routine examinations. NSS in kidney allografts is a safe procedure with preservation of renal function.

(c) 2020 S. Karger AG, Basel
\end{abstract}

\section{Introduction}

The development of malignancy in patients following allograft transplantation is an uncommon but well-recognized complication. The risk of de novo primary renal cell carcinoma (RCC) in renal transplant patients is 100 times higher than that in the general population [1], with most cases occurring in native kidneys and only $10 \%$ of RCC occurring in allograft kidneys [2]. The mean time between transplantation and the detection of kidney allograft RCC is reported to be more than 10 years $[2,3]$. Nephron sparing surgery (NSS) was first proposed for transplanted patients in 2005. Barama et al. [4] described 5 patients undergoing NSS 4-17 years after transplantation. All included patients retained kidney function for $\geq 2$ years, and no early RCC recurrence was described. In 2014, Tillou et al. [5] conducted a multicentre study and presented 79 cases with de novo tumours in renal grafts. Among these patients, 43 underwent NSS, with subsequent preservation of graft function in 41 patients. Herein, we want to share our experience and present the favourable outcome of 2 patients with RCC in their grafts who underwent NSS.

\section{Case Presentation}

\section{Patient 1}

In 1991, a 46-year-old man underwent renal transplantation for end-stage renal failure due to cirrhotic kidneys. At the age of 73 (27 years after transplantation), follow-up ultrasound revealed a mass in the upper pole of the kidney allograft (Fig. 1). Abdominal MRI also showed a mass $41 \times 33 \times 31 \mathrm{~mm}$ in size with cystic components within the upper pole (Fig. 2). These imaging findings were strongly suggestive of malignancy. Suspicion was confirmed by a CT-guided puncture of the mass. Histology of the respective biopsies showed papillary variants of RCC. Due to the diagnostic results, we recommended NSS. The NSS technique was performed karger@karger.com

www.karger.com/uin

Karger $\stackrel{2}{=}$ (c) 2020 S. Karger AG, Base

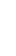

Frank Friedersdorff

Department of Urology, Charité - Universitätsmedizin Berlin

Hindenburgdamm 30

DE-12203 Berlin (Germany)

Frank.Friedersdorff@ charite.de 


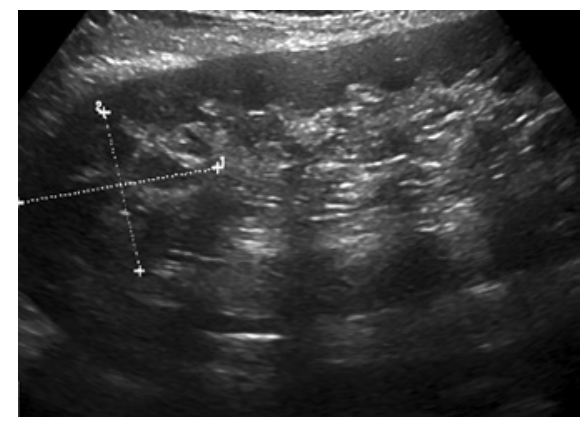

Fig. 1. Ultrasound of the kidney graft with a 34-mm renal mass in the upper pole. Ultrasound follow-up performed before surgery showing de novo renal mass.

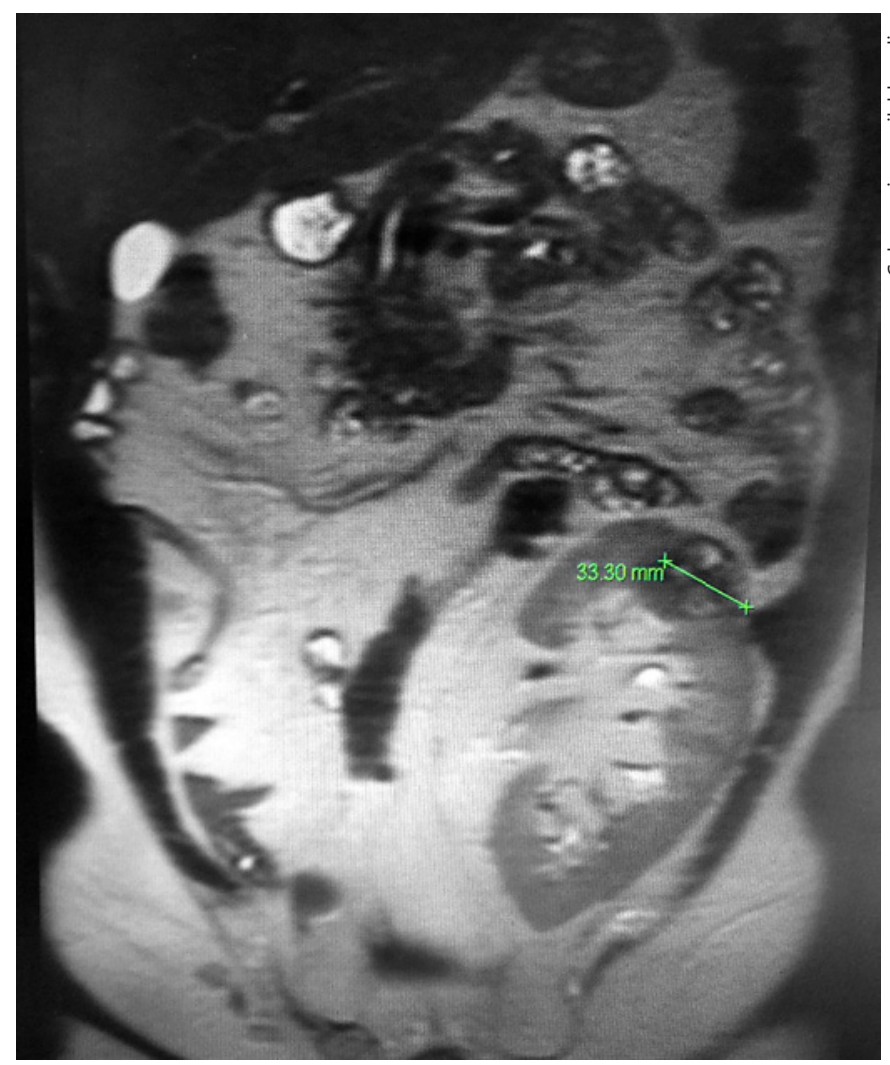

Fig. 2. MRI abdomen with a renal mass of $41 \times 33 \times 31 \mathrm{~mm}$ with cystic components in the upper pole of the kidney graft. Axial MRI scan showing a renal mass before surgery.

by a pararectal incision. After uncovering the upper renal pole with tumour, the renal hilus was controlled by clamping, the tumour was resected with a $1-\mathrm{mm}$ safety margin, and hemostasis was performed. After unclamping of the hilus, a drainage was placed. The operation time was $2: 40 \mathrm{~h}$, and the volume of blood loss was estimated as $700 \mathrm{~mL}$. The postoperative serum Cr level was reported stable undulant at $0.94 \mathrm{mg} / \mathrm{dL}$.

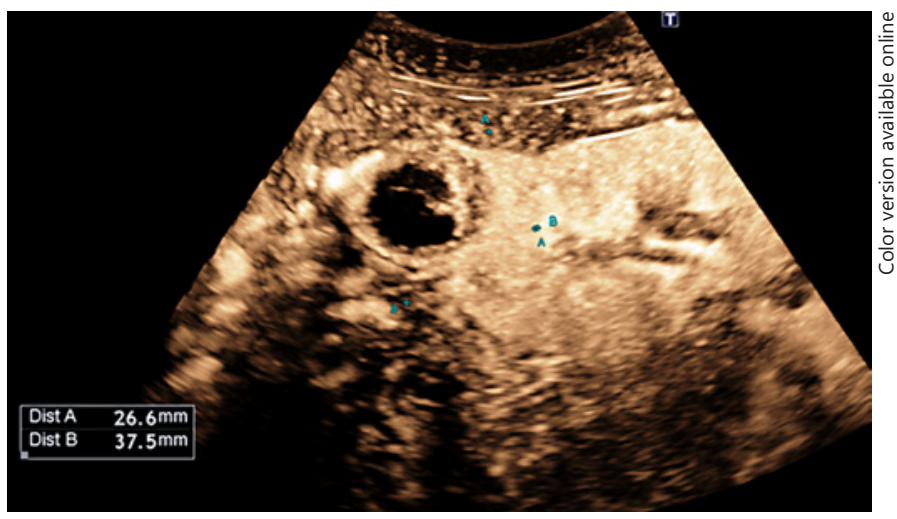

Fig. 3. Ultrasound with a $26 \times 37-\mathrm{mm}$ renal mass in the mid-level of the kidney graft. Ultrasound follow-up performed before surgery showing de novo renal mass.

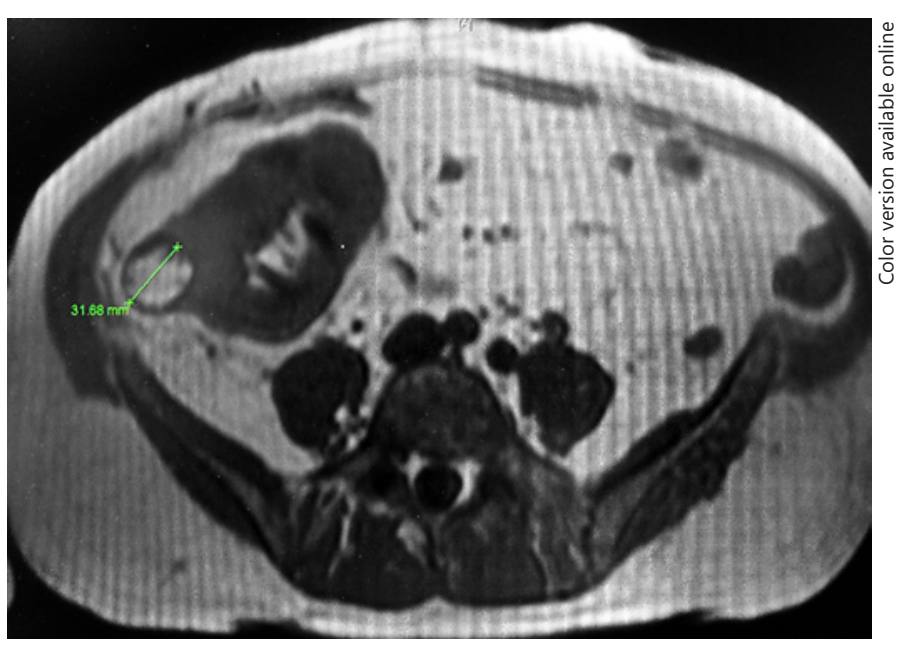

Fig. 4. MRI abdomen with a mass lesion of $40 \times 39 \times 31 \mathrm{~mm}$ with cystic components in the mid-level of the kidney graft. Axial MRI scan showing a renal mass before surgery.

\section{Patient 2}

In 2003, a 36-year-old man underwent renal transplantation for end-stage renal failure due to "Alport syndrome." At age 50 years (14 years after transplantation), a renal mass was diagnosed by ultrasound in the mid-level of the kidney allograft (Fig. 3). Abdominal MRI also revealed a renal lesion of $40 \times 39 \times 31 \mathrm{~mm}$ size with cystic components in the mid-level of the transplant (Fig. 4). The patient was referred to our hospital in order to undergo NSS for the suspected RCC. The NSS technique was also performed by a pararectal incision. After uncovering the mid-level of the transplant with the containing tumour, the renal hilus was controlled by clamping, the tumour was resected with a $2-\mathrm{mm}$ safety margin, and final hemostasis was performed. After unclamping of the hilus, a drainage was also placed. The operation time was 2:16 h, and the estimated blood loss was $300 \mathrm{~mL}$. The postoperative serum $\mathrm{Cr}$ level was reported stable undulant at $2.34 \mathrm{mg} / \mathrm{dL}$. 
In both cases, the pathological findings showed negative margins; the histological type was papillary RCC pT1a G2 R0 V0. The mean diameter was minimum $39 \mathrm{~mm}$. We performed transabdominal ultrasound and abdominal and pelvic MRI yearly after the surgery. No recurrence of RCC was reported. Both patients still have normal renal transplant function $(0.83$ and $1.86 \mathrm{mg} / \mathrm{dL})$ with no indication for dialysis (25 and 32 months after NSS).

\section{Discussion/Conclusion}

Kidney transplant recipients experience a disproportionately greater incidence of RCC than the general population [1]. The risk increases with dialysis preceding transplantation as well as hypertensive nephrosclerosis and vascular diseases, with the trend more apparent for papillary RCC than clear cell RCC [6]. The survival difference is mainly due to differences in stage and grade. However, the presence of metastasis may predict outcomes. Therefore, posttransplantation monitoring of allograft function and screening for posttransplant malignancies seem to be important. NSS seems to be a good alternative to radical nephrectomy in small tumours, with a low risk of recurrence in the remaining parenchyma $[4,5]$. This is comparable with our experience in the presented 2 cases. Both patients had a small tumour $(<4 \mathrm{~cm})$ with no recurrence 25 and 32 months after NSS. Current evidence demonstrated that the 5-year recurrence-free rate of RCC patients with pT1a disease was $98 \%$ after total nephrectomy and $97 \%$ after NSS [7]. However, the local recurrence rates are comparable to those of partial nephrectomies on native kidneys [8]. In the transplant setting, preservation of renal function with NSS is an attractive tool for the management of small renal masses $(<4 \mathrm{~cm})$ in a renal graft [9]. Active surveillance and radiofrequency ablation may be used in select cases. Given the improved convalescence and smaller incision size, the use of robotic-assisted laparoscopic partial nephrectomy in renal allograft mass can be an attractive option prospectively but needs further investigation as shown in a case report by Kaouk et al. [10].

In conclusion, NSS is a safe procedure for patients with RCC in a renal graft. By choosing NSS for treatment, preservation of graft function can be achieved, without the need for dialysis. Especially in patients with small tumour size, NSS should be the treatment of choice.

\section{Statement of Ethics}

The patients have given written informed consent to publish the cases (including publication of images).

\section{Conflict of Interest Statement}

The authors have no conflicts of interest to declare.

\section{Funding Sources}

The authors did not receive any funding for these case reports.

\section{Author Contributions}

Mandy Hubatsch: The author contributed to this work by conducting literature search, collecting data, interpreting the data, and preparing the manuscript. Robert Peters: The author contributed to this work by collecting data, interpreting the data, editing the manuscript, and revising the draft critically. Andreas Maxeiner: The author contributed to this work by collecting data, interpreting the data, editing the manuscript, and revising the draft critically. Nasrin El-Bandar: The author contributed to this work by collecting data, interpreting the data, editing the manuscript, and revising the draft critically. Sarah Weinberger: The author contributed to this work by collecting data, interpreting the data, editing the manuscript, and revising the draft critically.

\section{References}

1 Doublet JD, Peraldi MN, Gattegno B, Thibault $P$, Sraer JD. Renal cell carcinoma of native kidneys: prospective study of 129 renal transplant patients. J Urol. 1997 Jul;158(1):42-4.

2 Penn I. Primary kidney tumors before and after renal transplantation. Transplantation. 1995 Feb;59(4):480-5.

3 Tillou X, Doerfler A, Collon S, Kleinclauss F, Patard JJ, Badet L, et al. De novo kidney graft tumors: results from a multicentric retrospective national study. Am J Transplant. 2012 Dec; 12(12):3308-15

4 Barama A, St-Louis G, Nicolet V, Hadjeres R, Daloze P. Renal cell carcinoma in kidney allografts: a case series from a single center. Am J Transplant. 2005 Dec;5(12):3015-8.
5 Tillou X, Guleryuz K, Doer, er A, Bensadoun $H$, Chambade D, et al. Nephron sparing surgery for de novo kidney graft tumor: results from a multicentre national study. Am J Transplant. 2014 Sep;14(9):2120-5.

6 Karami S, Yanik EL, Moore LE, Pfeiffer RM, Copeland G, Gonsalves L, et al. Risk of renal cell carcinoma among kidney transplant recipients in the United States. Am J Transplant. 2016 Dec;16(12):3479-89.

7 Mehrazin R, Smaldone MC, Egleston B, Tomaszewski JJ, Concodora CW, Ito TK, et al. Is anatomic complexity associated with renal tumor growth kinetics under active surveillance? Urol Oncol. 2015 Apr;33(4):167.
8 Ljungberg B, Albiges L, Abu-Ghanem Y, Bensalah K, Dabestani S, Fernández-Pello $\mathrm{S}$, et al. European association of urology guidelines on renal cell carcinoma: the 2019 update. Eur Urol. 2019 May;75(5):799-810.

9 Kitagawa Y, Nakashima K, Shima T, Izumi K, Narimoto K, Miwa S, et al. Clinicopathological outcomes of clinical T1a renal cell carcinoma by tumor size. Jpn J Clin Oncol. 2011 May; 41(5):637-41

10 Kaouk JH, Spana G, Hillyer SP, White MA, Haber GP, Goldfarb D. Robotic-assisted laparoscopic partial nephrectomy for a $7-\mathrm{cm}$ mass in a renal allograft. Am J Transplant. 2011 Oct; 11(10):2242-6. 